\title{
PRIMARY STRUCTURE OF CARBOXYPEPTIDASE III FROM MALTED BARLEY
}

\author{
by \\ STEEN BECH SØRENSEN, IB SVENDSEN and KLAUS BREDDAM \\ Department of Chemistry, Carlsberg Laboratory, \\ Gamle Carlsberg Vej 10, DK-2500 Copenhagen Valby
}

Keywords: Amino acid sequence, sequence homology, serine carboxypeptidase

The primary structure of malt carboxypeptidase III has been determined. The enzyme is a single N-terminally blocked polypeptide chain containing 411 amino acid residues. The sequence of these amino acid residues was deduced from analysis of fragments of the polypeptide chain obtained by chemical cleavages with either cyanogen bromide or hydroxylamine and by enzymatic cleavages with either trypsin, S. aureus V8 protease or proteinase $A$ from yeast. A glycosylated asparagine was found in position 71 .

The determined sequence was $97 \%$ homologous with the amino acid sequence derived from the nucleotide sequence of a gene coding for a wheat protein postulated to be a carboxypeptidase. The malt carboxypeptidase III sequence showed $34 \%$ homology with the amino acid sequence of the single-chain carboxypeptidase $Y$, and about $25 \%$ homology with the combined A- and B-chains of malt carboxypeptidase I and II as well as wheat carboxypeptidase II.

\section{INTRODUCTION}

Carboxypeptidases play an important role in hydrolysis of reserve proteins in temperate zone cereals (21). In germinating barley L. MIKOLA (16) has suggested the presence of five carboxypeptidases with different substrate preferences and three of these, carboxypeptidase I, II and III have been purified and characterized in this laboratory $(6,7,8)$. The amino acid sequences of malt carboxypeptidases I (19) and II (20) and wheat carboxypeptidase II (9) are known and all three enzymes consist, like a number of other serine carboxypeptidases from higher plants (4), of two subunits, each composed of two polypeptide chains, cross-linked by disulphide bridges (8). Recently, DOAN \& FINCHER (10) reported the isolation of a cDNA clone encoding both peptide chains of malt carboxypeptidase I, indicating that these chains are formed by excision of a 55-residue long linker peptide from a single precursor polypeptide. The amino acid sequence of the two peptide chains are homologous with the $\mathrm{N}$-terminal and C-terminal portion, respectively, of the singlechain carboxypeptidase $Y$ from yeast $(5,15,18)$. In the present report, the primary structure of malt carboxypeptidase III has been determined, and it is demonstrated that the sequence of this single peptide chain is almost identical to the amino acid sequence derived from the nucleotide sequence of a wheat gene (2) and homologous with the two peptide chains of malt carboxypeptidases I and II and the single peptide chain of carboxypeptidase $\mathrm{Y}$.

Abbreviations: DPCC = diphenylcarbamyl chloride; EDTA = ethylenediaminetetraacetic acid, disodium salt; GYBS-Sepharose $=[(\mathrm{N}$-glycyl-L-tyrosine $)$-p-azo-benzyl $]$ succinyl-Sepharose $4 \mathrm{~B} ; \mathrm{HPLC}=$ high performance liquid chromatography; PTH = phenylthiohydantoin; TFA = trifluoroacetic acid. 


\section{MATERIALS AND METHODS}

\subsection{Materials}

Malt carboxypeptidase III was prepared as previously described (6) from malted Gula barley (obtained from the Carlsberg Breweries, Denmark) by affinity chromatography on GYBS-Sepharose.

Bio-Gels P-60 and P-6 were from Bio-Rad, USA. DPCC-treated trypsin and dithiothreitol were from Sigma, USA. S. aureus V8 protease was from ICN ImmunoBiologicals, USA. Proteinase A from yeast was a gift from $\mathrm{dr}$. Thomas DREYER, Carlsberg Laboratory. 2Vinylpyridine was from Aldrich, W. Germany. Reagents and solvents used in sequencing were from Applied Biosystems, USA. All other chemicals were analytical or HPLC-grade from Merck, W. Germany.

\subsection{Methods}

\subsubsection{Cleavage of peptide bonds}

Malt carboxypeptidase III was reduced and pyridylethylated and subsequently cleaved with cyanogen bromide, hydroxylamine or trypsin as previously described $(7,19)$. Digestion of the modified enzyme with $\mathrm{S}$. aureus V8 protease (EC 3.4.21.19) (13) was performed at $37^{\circ} \mathrm{C}$ in $0.1 \mathrm{M}$ ammonium bicarbonate and $2 \mathrm{M}$ urea at $\mathrm{pH}$ 7.8. The protein was dissolved in $6 \mathrm{M}$ urea and diluted with 2 volumes $0.15 \mathrm{M}$ ammonium bicarbonate $\mathrm{pH} 7.8$, enzyme was added (1:30 $\mathrm{w} / \mathrm{w}$ ) and the reaction stopped after 6 or 24 hours digestion by addition of acetic acid to a final concentration of $15 \%$.

Digestion of the reduced and alkylated enzyme with proteinase A from yeast (EC 3.4.23.6) was performed in $0.1 \mathrm{M} \mathrm{Na}$-formate and $2 \mathrm{M}$ urea at $\mathrm{pH} 3.0$ and $25^{\circ} \mathrm{C}$. The protein was dissolved in $6 \mathrm{M}$ urea and two volumes $0.15 \mathrm{M} \mathrm{Na}$-formate pH 3.0 were added. Enzyme $(1: 100 \mathrm{w} / \mathrm{w})$ was added and the solution stirred for 6 hours at $25^{\circ} \mathrm{C}$. Proteinase A was inactivated by heating for $5 \mathrm{~min}$ in a boiling waterbath (11).

\subsubsection{C-terminal sequence determination}

The C-terminal amino acid sequence of the native enzyme was determined by digestion with wheat carboxypeptidase II. The following condi- tions were used: $0.1 \mathrm{mM}$ malt carboxypeptidase III, 50 mM sodium acetate, 1 mM EDTA, $\mathrm{pH} 4.5$, $0.2 \mu \mathrm{M}$ wheat carboxypeptidase II (mol. weight 55,000 ). At suitable time intervals aliquots were withdrawn, $\mathrm{pH}$ adjusted to 2.0 by addition of $0.5 \mathrm{M} \mathrm{HCl}$ and the aliquots applied directly to a Durrum D500 amino acid analyzer.

\subsubsection{Separation of peptide fragments}

Separation and purification of peptide fragments were performed by chromatography on Bio-Gel P-60 in 30\% (v/v) acetic acid or by reverse phase HPLC using equipment from Waters and columns i.d. $4.6 \mathrm{~mm}$ and length 25 $\mathrm{cm}$. The HPLC columns employed were Vydac 214TP54 Protein $\mathrm{C}_{4}$, preferentially applied for isolation of large peptides and $\mathrm{Vydac} 218 \mathrm{TPb}$ or J.T. Baker RP7104-0 wide pore $C_{18}$ columns applied for smaller fragments. Gradient elution was accomplished with linear gradients of acetonitrile in $0.1 \%(\mathrm{w} / \mathrm{w})$ trifluoroacetic acid at a flow rate of $1.0 \mathrm{ml} \cdot \mathrm{min}^{-1}$. The eluate was monitored at $215 \mathrm{~nm}$ supplemented with fluorescence detection at $375 \mathrm{~nm}$ after excitation at $280 \mathrm{~nm}$, to detect tryptophan containing peptides. Inhomogeneous fractions were rechromatographed in the same system but employing a more flat and narrow gradient of acetonitrile, or another column. Appropriate peaks in the chromatograms were lyophilized or taken to dryness on a Savant Speed Vac Concentrator before sequence analysis and amino acid analysis.

\subsubsection{Amino acid sequence determinations}

Peptides were sequenced either on a Beckman Model $890 \mathrm{C}$ liquid phase sequencer as previously described (14) or on an Applied Biosystems Model $470 \mathrm{~A}$ gas-phase sequencer, using the program provided by the company. The phenylthiohydantoin amino acid derivatives from the gas-phase sequencer were identified on-line by reverse phase HPLC using an Applied Biosystems Model 120A PTH-analyser, while those from the liquid phase sequencer were identified with a Hewlett-Packard HPLC system using a linear gradient from 10 to $45 \%$ methanol (17). Amino acid compositions were determined as previously described (7). 


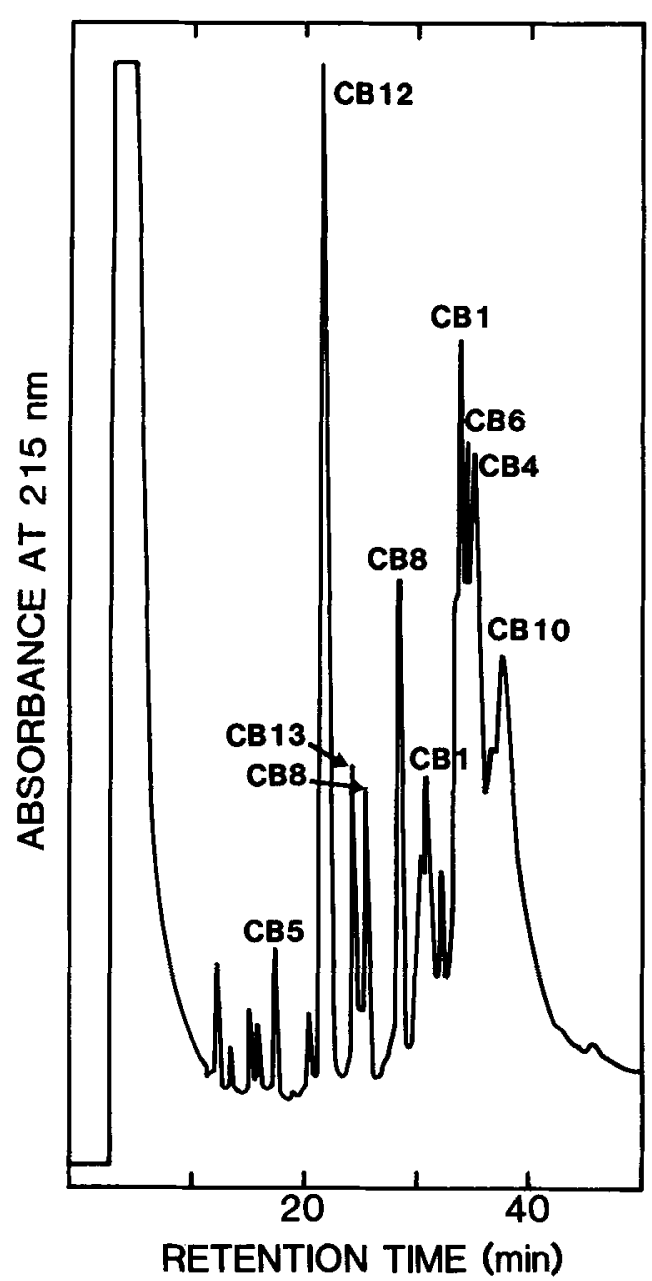

Figure 1. Separation of soluble cyanogen bromide fragments of malt carboxypeptidase III $(1 \mathrm{mg})$ by reverse phase HPLC using a wide pore $\mathrm{C}_{18}$ column (Bakerbond). Elution was accomplished over $60 \mathrm{~min}$ with a linear gradient from 0 to $54 \%$ acetonitrile in $0.1 \%$ TFA at a flow rate of $1.0 \mathrm{ml} \cdot \mathrm{min}^{-1}$. The eluate was monitored at $215 \mathrm{~nm}$.

\subsubsection{Peptide nomenclature}

Peptide fragments obtained by cleavage with cyanogen bromide, hydroxylamine, trypsin, $\mathrm{S}$. aureus $V 8$ protease or proteinase $A$ from yeast are designated $\mathrm{CB}, \mathrm{NG}, \mathrm{T}, \mathrm{E}$ and $\mathrm{A}$, respectively, followed by a number indicating their positions in the polypeptide chain from the $\mathrm{N}$-terminus of the protein. Similarly, fragments originating from cleavage of Asp-Pro bonds in acidic solu- tion during cleavage with cyanogen bromide are named DP followed by their position in and the name of the corresponding cyanogen bromide fragment.

\section{RESULTS}

\subsection{N-terminal sequence}

$\mathrm{N}$-terminal sequence determination of the reduced and alkylated enzyme showed the polypeptide chain to be N-terminally blocked. The blocking group was both acid and base labile. Heterogeneity at the $\mathrm{N}$-terminus was observed as the cyanogen bromide peptide CB1 was obtained in two forms, one form missing the first three amino acid residues.

\subsection{Cyanogen bromide fragments}

According to the amino acid analysis, malt carboxypeptidase III contains 12 methionyl residues (6) corresponding to 13 cyanogen bromide fragments. Cyanogen bromide cleavage of reduced and pyridylethylated malt carboxypeptidase III resulted in a supernatant and a precipitate of fragments insoluble at $\mathrm{pH}$ 3.5.

The supernatant was subjected to HPLCchromatography which revealed 6 major peaks

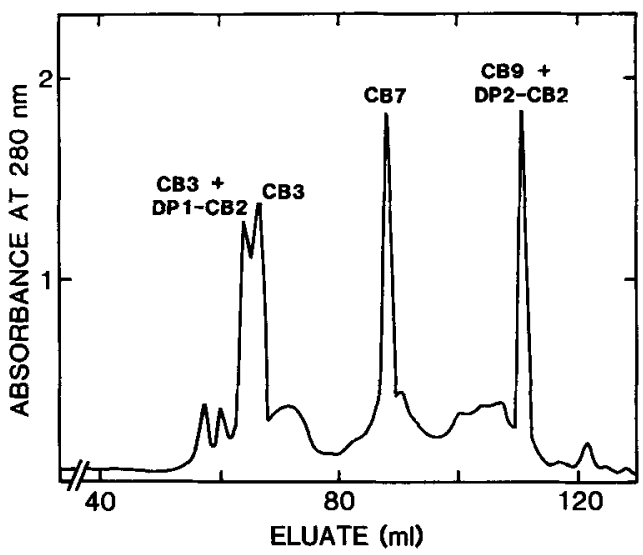

Figure 2. Separation of dissolved precipitate (pH 3.5) of cyanogen bromide fragments of malt carboxypeptidase III $(1 \mathrm{mg})$ on Bio-Gel P-60 $(1.5 \times 90 \mathrm{~cm})$. The eluant was $30 \%$ acetic acid at a flow rate of $1.3 \mathrm{ml} \cdot \mathrm{h}^{-1}$. The eluate was monitored at $280 \mathrm{~nm}$ and fractions of $1.3 \mathrm{ml}$ collected. 


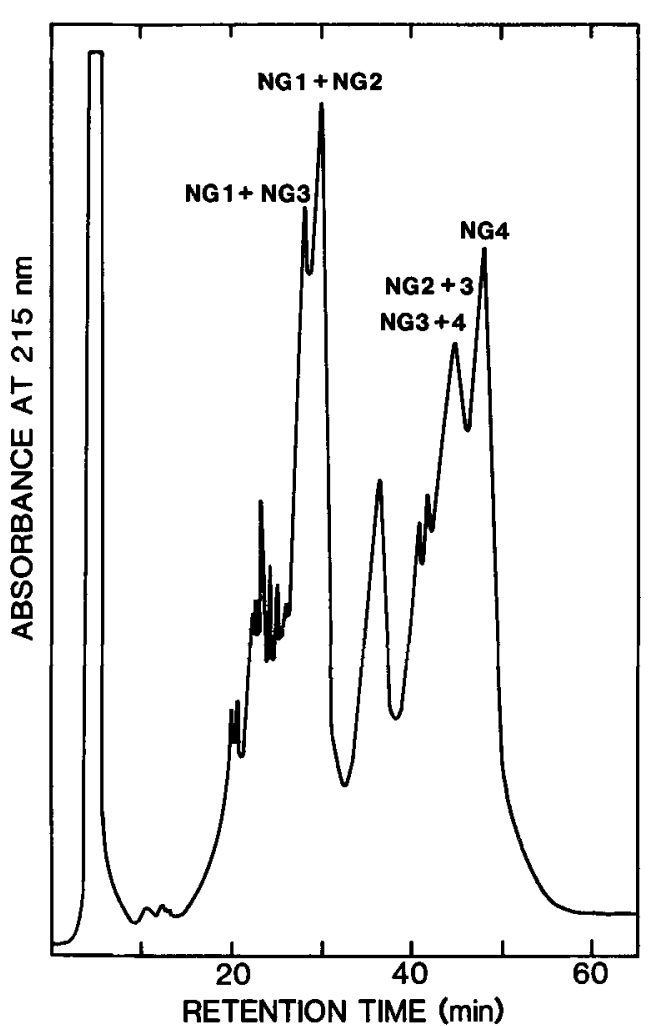

Figure 3. Separation of hydroxylamine fragments of malt carboxypeptidase III $(1.2 \mathrm{mg})$ by reverse phase HPLC using a protein $\mathrm{C}_{4}$ column from Vydac. A linear gradient over $60 \mathrm{~min}$ from 27 to $63 \%$ acetonitrile in $0.1 \%$ TFA at a flow rate of $1.0 \mathrm{ml} \cdot \mathrm{min}^{-1}$ was applied for elution. The eluate was monitored at $215 \mathrm{~nm}$.

and 4 minor peaks. Sequence analysis allowed partial or complete determination of the primary structures of the following cyanogen bromide fragments: CB1, CB4, CB5, CB6, CB8, CB10, $\mathrm{CB} 12$ and $\mathrm{CB} 13$ (Figures 1 and 6). Several of the cyanogen bromide fragments were found in two peaks (e.g. CB8) presumably due to different retention times for peptides containing homoserine and homoserine lactone as the $\mathrm{C}$-terminal residue.

Cyanogen bromide fragments in the precipitate were dissolved in $30 \%$ acetic acid and separated on Bio-Gel P-60 (Figure 2). In this way the partial amino acid sequences of cyanogen bromide fragments DP1-CB2, DP2-CB2, CB3, $\mathrm{CB} 7$ and $\mathrm{CB} 9$ were obtained (Figure 6).

\subsection{Hydroxylamine fragments}

The fragments formed by cleavage with hydroxylamine could be purified by HPLC-chromatography on a Vydac $\mathrm{C}_{4}$ column (Figure 3). Cleavage or separation was apparently incomplete as the same $\mathrm{N}$-terminal sequence was found in several peaks. The NG4-fragment could be sequenced 49 cycles and gave the overlaps between CB4, CB5, CB6 and CB7. The NG3 fragment provided overlap between two tryptic peptides (T17 and T18+19) (Figure 6).

\subsection{Tryptic peptides}

The amino acid composition of malt carboxypeptidase III indicated 24 Lys and $17 \mathrm{Arg}$ residues (6), corresponding to 42 tryptic peptides. HPLC-chromatography of the digestion

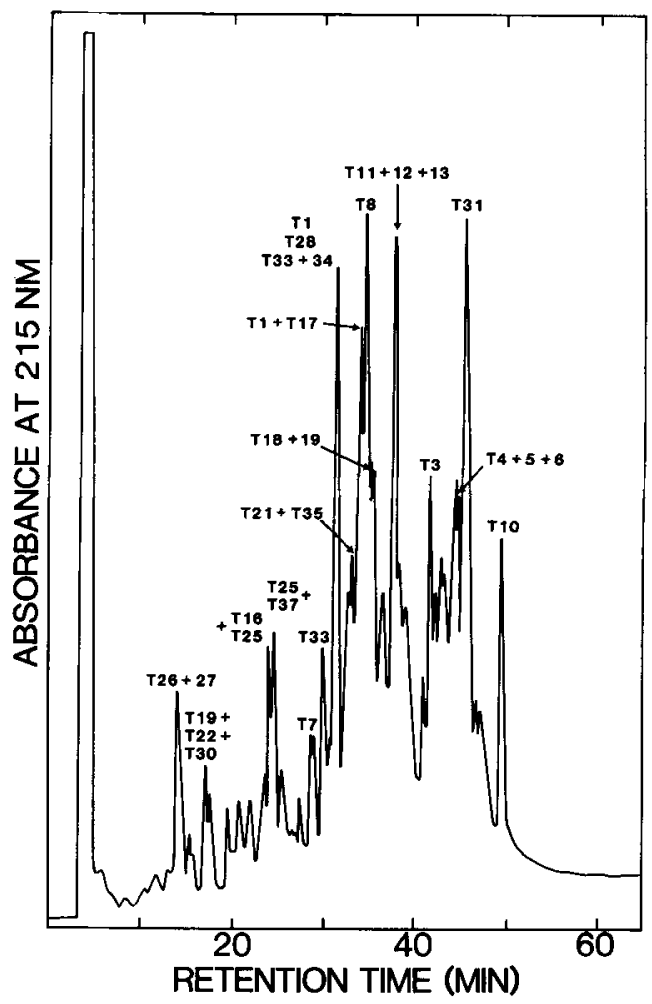

Figure 4. Fractionation of a tryptic digest of malt carboxypeptidase III $(0.8 \mathrm{mg})$ by reverse phase HPLC using a wide pore $\mathrm{C}_{18}$ column (Bakerbond). Elution was accomplished over $60 \mathrm{~min}$ with a gradient from 0 to $54 \%$ acetonitrile in $0.1 \%$ TFA at a flow rate of 1.0 $\mathrm{ml} \cdot \mathrm{min}^{-1}$. The eluate was monitored at $215 \mathrm{~nm}$. 
S.B. SøRENSEN et al.: Sequence of malt carboxypeptidase III

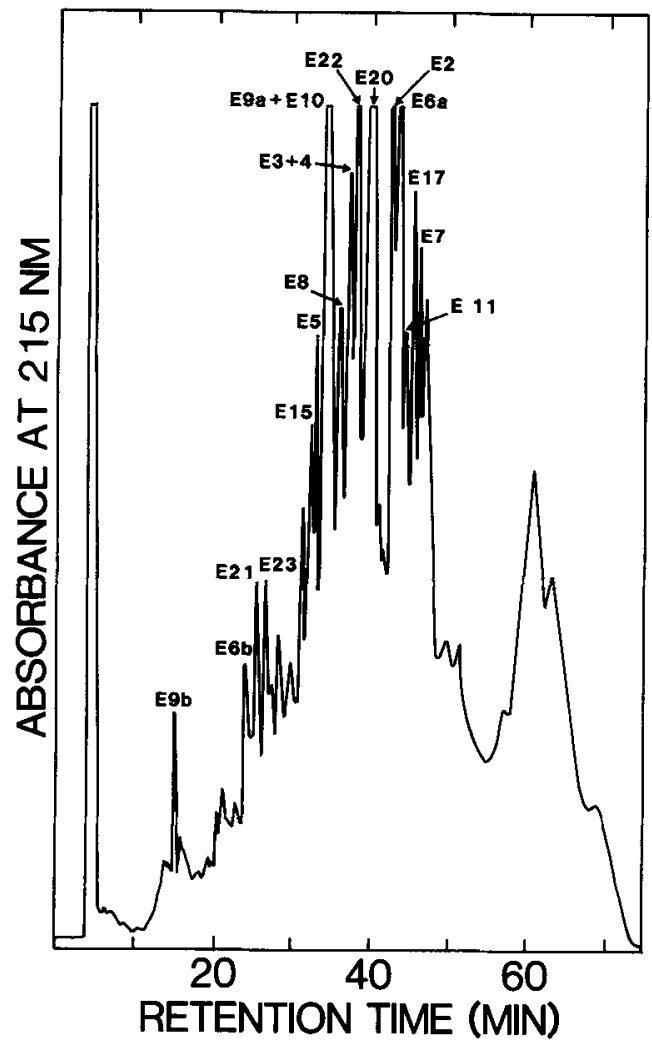

Figure 5. Separation of S. aureus V8 protease fragments from malt carboxypeptidase III $(0.7 \mathrm{mg})$ by reverse phase HPLC using a wide pore $\mathrm{C}_{18}$ column (Bakerbond). A linear gradient over $60 \mathrm{~min}$ from 0 to $54 \%$ acetonitrile in $0.1 \%$ TFA at a flow rate of 1.0 $\mathrm{ml} \cdot \mathrm{min}^{-1}$ was applied for elution. The eluate was monitored at $215 \mathrm{~nm}$.

mixture revealed a complex chromatogram with fairly well resolved peaks (Figure 4). Isolated fragments were sequenced as far as possible. Incomplete tryptic cleavages were observed at repeated basic residues and at a basic residue followed by an acidic residue (Figure 6).

\subsection{S. aureus V8 protease fragments}

The reduced and alkylated malt carboxypeptidase III was digested with S. aureus V8 protease. The resulting fragments were separated by reverse phase HPLC (Figure 5). Sequence analysis of the separated fragments contributed valuable sequence information, e.g. missing overlaps, especially between tryptic fragments. Two unexpected cleavages occurred at Gly ${ }^{95}$ $\mathrm{Thr}^{96}$ and $\mathrm{Ala}^{153}-\mathrm{Ser}^{154}$ (Figure 6) and the latter provided, after isolation of both E9a, E9b and E9, a missing overlap. E9 was obtained after digestion of fragment NG2 and E16 was isolated by HPLC after cleavage of CB7 with S. aureus V8 protease.

\subsection{Proteinase A fragments}

Throughout the sequence determination comparisons with the amino acid sequence derived from the nucleotide sequence of the corresponding carboxypeptidase from wheat (2) facilitated the alignment of the isolated fragments. An overlap was missing between E5 and E6 and a stretch connecting E20 with T33+34 (Figure 6). This information was obtained by digestion of reduced and alkylated malt carboxypeptidase III with proteinase $\mathrm{A}$ from yeast and isolation of the fragments $\mathrm{A} 1$ and $\mathrm{A} 2$ by HPLC.

\subsection{Assignment of glycosylated asparagines and $\mathbf{C}$-terminus}

Malt carboxypeptidase III contains 2 glucosamine residues (6). These were assigned to the glycosylated asparagine $\mathrm{Asn}^{71}$ due to the absence of a PTH-amino acid in this position after Edman degradation of fragment E6a and $\mathrm{NG} 2$ and the presence of a hydroxyamino acid two positions from the vacant position towards the C-terminal end. Furthermore, amino acid analysis of NG2 indicated the presence of glucosamine.

Digestion of native malt carboxypeptidase III with wheat carboxypeptidase II identified the three amino acid residues at the $\mathrm{C}$-terminus to be -Lys-Leu-Lys.

\section{DISCUSSION}

The amino acid sequence of malt carboxypeptidase III is consistent with this enzyme being composed of a single $\mathrm{N}$-terminally blocked polypeptide chain, 411 amino acid residues long (Figure 6). The polypeptide chain is polymor- 


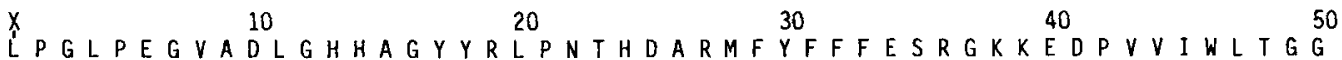
$152+11$ $60 \quad 70_{+} \quad 80 \quad 90$

90

PGCSSELAVFYENGPFTI AN NMSLVWNKFGWDKISNIIFVDQPTGTGFSY DP2-CB2 CB3

SSDDRDTR P DET GVSNDL Y F L Q VFF K K H P E F I K N D F F I T GE S Y A G H Y I P AFASRVHQGNKKNEGTHINLKGFAIGNGLTDPAI (

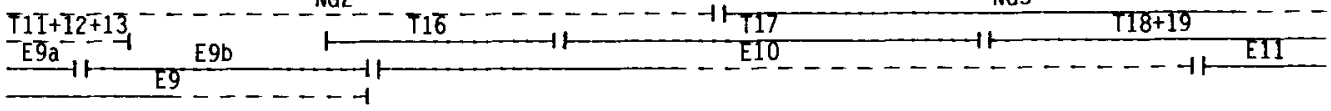
$210 \quad 220 \quad 230 \quad 240 \quad 250$

K A D Y ERINKFIPPCEFAIKLCGTNGKASCMAAYMVCNTIFNSIMKLVGTK

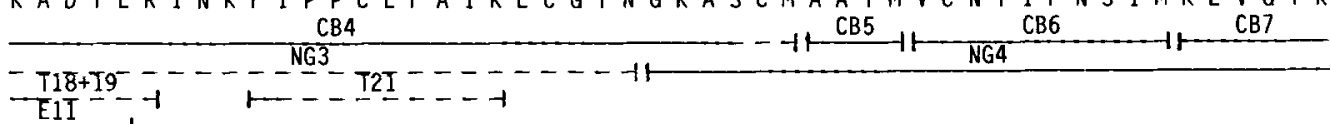
$260 \quad 270 \quad 280 \quad 290 \quad 300$ NYYDVRKECEGKLCCYDFSNLEKFFGDKAVRQAIGVGDIEFVSCSTSVYQA …ㄱ․

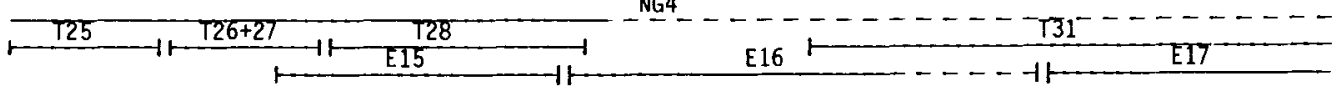
$3103320 \quad 330 \quad 340 \quad 350$

MLTDWMRNLEVG I PALLEDG IN VLI YAGEYDLICN WLGNSRWVHSMEWSG

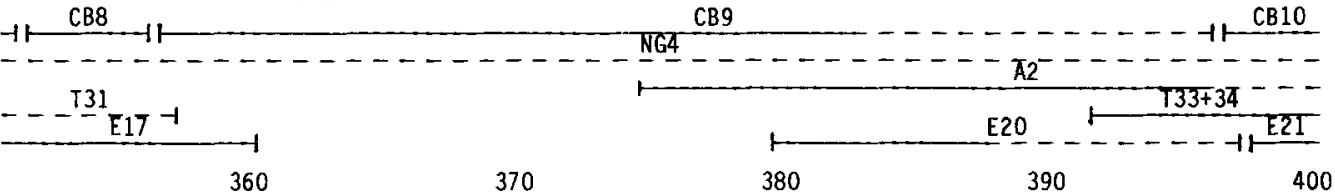
QKDFAKTAESSFLVDDAOAGVLKSHGALSFLKVHNAGHMVPMDOPKAALE CB10 $T 3 \overline{3}+\overline{3} 4^{-1}$

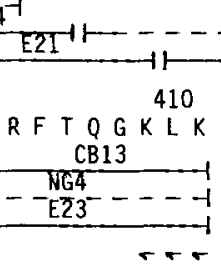

Figure 6. Amino acid sequence of malt carboxypeptidase III. Peptides were sequenced by automated Edman degradation (full line) and digestion with wheat carboxypeptidase II ( - ). Each peptide fragment is indicated by a full line for sequenced residues followed by a broken line for residues not sequenced in that particular fragment. Peptide fragments are designated by the following nomenclature: CB, cyanogen bromide fragments; NG, hydroxylamine fragments; T, tryptic fragments; E, S. aureus V8 protease fragments; A, proteinase A fragments; DP, Asp-Pro split during cleavage with cyanogen bromide in acidic solution. $\stackrel{+}{\mathrm{N}}$ is a glycosylated asparagine and $\mathrm{X}$ the unknown N-terminal blocking group. 
S.B. SøRENSEN et al.: Sequence of malt carboxypeptidase III

CPD-WIII: MATTPRLASLLLLLALCAAAAGALRLPPDASFPGAQAERLIRALNLLPGRPRRGL

$60070 \quad 8000000$

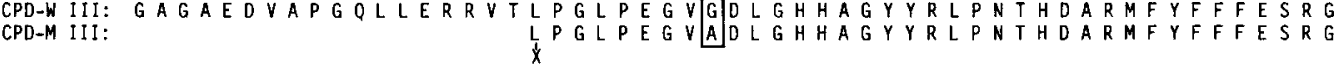
120

$130 \quad 140$

150

160

CPD-W III: KKEDPVVIWLTGGPGCSSELAVFYENGPFTIANNMSLVWNKFGWDKISNIIFVDP CPD-M III: KKEDPVVIWLTGGPGCSSELAVFYENGPF I IANNMSLVWNKFGWDKISN I IFVDQ

CPD-W 11I: ATGTGFSYSSDDRDTRHDE同GVSNDLYDFLQVFFKKHPEFWKNDFFITGESYAGH CPD-M III: [P] GTG G S Y S S D D R D T R H D E T G V S N D L Y D F L Q V V F F K K K H P E F I I K N D F F I I T G E S Y 230 240

250

260

270

CPD-W III: Y I PAFASRVHQGNKKNEGTHINLKGFAIGNGLIDPAIDYKAYTDYALDMNLIQKA

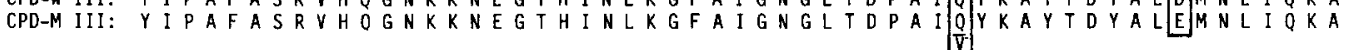
280

CPD-W III: DYDR INKFIPPCEFA IKLCGTDGKASCMAAYMVCN S10 I F N S I M KLVGTKNYYDVRK

310

320 CPD-M III: D Y E R I N K F I P P C E F A I K L C G T N G K A S C MAA A Y M V C N T I F N S I M K L V G T K N Y Y D V R K $340 \quad 350 \quad 360 \quad 370$

CPD-W III: ECEGKLCYDFSNLEKFFG DKAVROAIGVGDIEFVSCSTSYYOAMLTDWMRNLEYG CPD-M III: ECEGKLCYDFSNLEKFFGDKAVROAIGVGDIEFVSCSTSVYOAMLTDWMRNLEVG CPD-W III: I PALLEDGINVLIYA 390 E DLICN 410 G SRWVHSMEWSGOKDFAKTAESSFLVDDA CPD-M III: I PALLEDGINVLIYAGEYDLICNWLGNSRWVHSMEWSGOKDFAKTAESSFLVDDA $450 \quad 460 \quad 470 \quad 480$

CPD-W III: QAGVLKSHGALSFLKVHNAGHMVPMDQPKAALEMLRRFT QGKLKESVPEEEPATT CPD-M III: QAGVLKSHGALSFLKVHNAGHMVPMDOPKAALEMLRRFTQGKLK

CPD-W III: $F$ Y 500

Figure 7. Alignment of the amino acid sequence derived from the nucleotide sequence of a putative wheat carboxypeptidase (2) with that of malt carboxypeptidase III. Residues which are not identical are boxed. $\underset{+}{N}$ is a glycosylated asparagine and X the unknown N-terminal blocking group. CPD-W III = putative wheat carboxypeptidase, CPD-M III = malt carboxypeptidase III.

phous at position 185 , one form containing a glutamoyl, the other a valyl residue indicating the presence in barley of at least two genes each coding for one form. No evidence of polymorphism at other positions was found. The enzyme is a glycoprotein with a glycosylated asparagine at position 71 . No unused potential N-glycosylation sites were found and O-glycosylation was absent. The amino acid composition, as calculated from the sequence, is in fairly good agreement with the composition determined by amino acid analysis (6).

A comparison of the sequence of malt carboxypeptidase III with the nucleotide sequence of a putative wheat carboxypeptidase (2) revealed almost identity ( $97 \%$ homology) indicating that the malt and the wheat enzyme are functionally equivalent (Figure 7). The malt carboxypeptidase III sequence deviates in 10 positions from the putative wheat carboxypeptidase and all deviations except the polymorphic spot are the result of single base mutations. The distribution of the substitutions seems not to be random as they are concentrated in the central region of the sequences. This could be explained by the lack of important structures in this segment. A similar close homology was observed between carboxypeptidase II from malt and wheat $(9,20)$.

The amino acid sequence derived from the nucleotide sequence of the homologous wheat carboxypeptidase is extended both $\mathrm{N}$-terminally and C-terminally compared to the determined amino acid sequence of malt carboxypeptidase III (Figure 7). The N-terminal extension comprises apparently a signal peptide (2) and additionally about 50 amino acid residues before the homology with malt carboxypeptidases begins. This region could be a pro-peptide, indicating that the wheat enzyme and presumably the corresponding malt carboxypeptidase III are synthesized as inactive zymogens. The C-terminal extension which is 16 amino acid residues, suggests that the enzyme has been subject to proteolysis after its synthesis.

A comparison of the amino acid sequence of 
CPD-M I, A-chain: CPD-M II, A-chain: CPD-M IIJ:

CPD-Y:

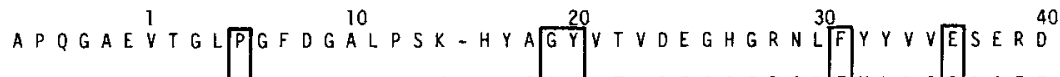

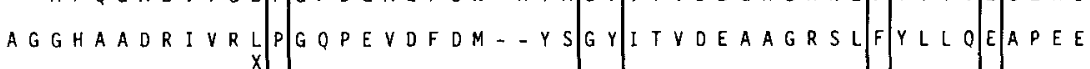

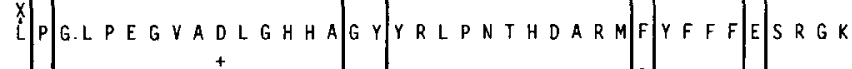

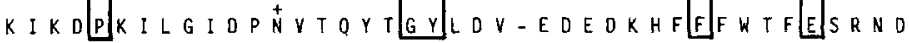

CPO-M I, A-chain: PGKDPVVLWLNGGPGCSSF D - GFVY国

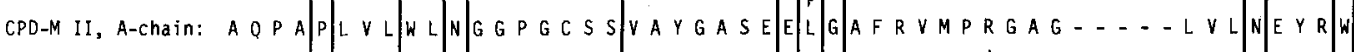
CPD-M III:

CPD-Y:

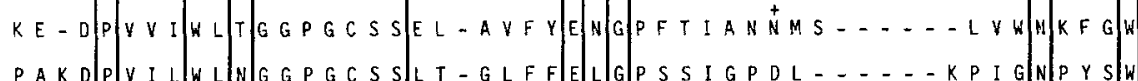
$P A K D D V I L L L] N G G P G C S S] L T-G L F F[E L G] P S S I G P D L \ldots$

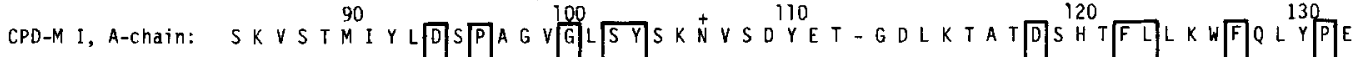

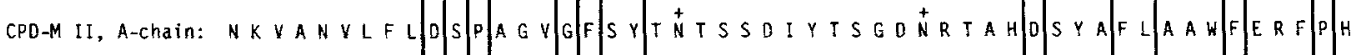
CPD-M III:

CPD-Y: OK I S N I I F V D D P P T G T G F S Y S S D D R D T R H - D E T G V S N D L Y Y D F L O V V F F K K K H P E E

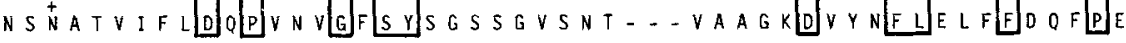

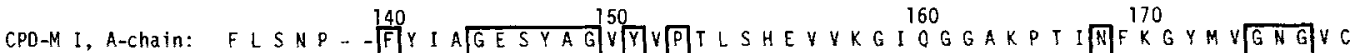

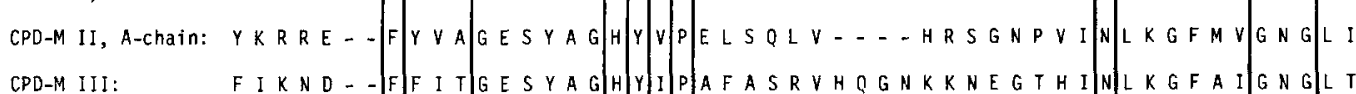

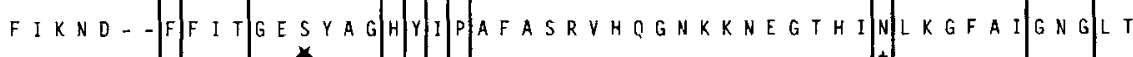
CPD-Y:

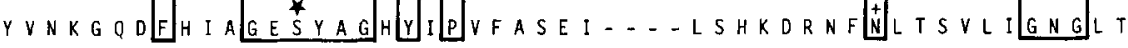
280 190 1900210 -chain: 200 CPD-M II, A-chain: DD D H Y YGTFEFWWNHGIVSDDTYRRLKDACLHDSFIHPSPACDAATDVAT CPD-M III: DPAI Y YKAYTDYALEMNLIQKADYER-... INKFIPPCEFAIKLCGTN-GK CPD-Y: D]PLTQYNYYEPMACGEGGEPSVLPSEECSAMEDSLERCLGLIESCYDSQSV

$$
240 \quad S 250
$$

CPD-M I, A-chain: SLISGLN I Y D I LE P - C Y HSR S CPD M I, B-chain:

GVP CM 270 - S DEVATAWL D

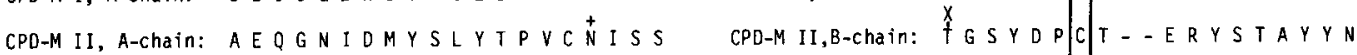
CPD-M III: ASCMAAYMVCNTIFNSIMKLVGTKNYYDVRKECEG-KLCCYDFSNLEKFFGD CPD-Y: WSCVPATIYCNNAQL-APYQRTGRNVYDIRKDCEGGNLCJYPILQDIODYLN

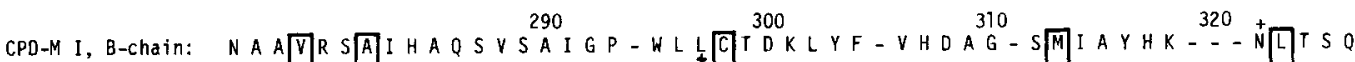

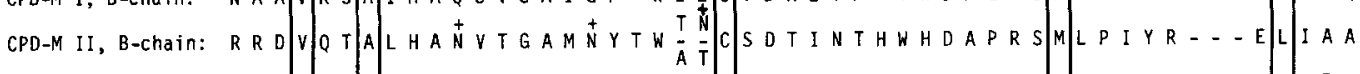
CPD-M III:

CPD-Y:

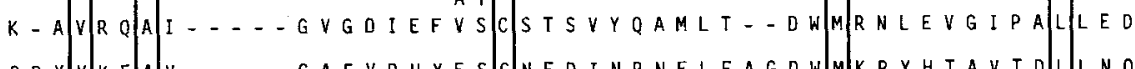

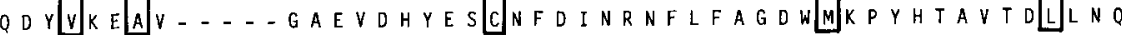

CPD-M I, B-chain:

3300340 360

CPO-M II, B-chain: G YRAIIF S G HDM GLRIWVFSGDTDAVVPLTATRYSIGAL-......... GLATTSWYPWYODLQ CPD-M III: GINVLIYAGEYDLICNWLGNSRWVHSMEWSGQKDFA- - KTAESSFLVDDAQ CPO-Y: DLPILVYAGDKDJFI CPO-M I, Buchain: VSGYTEGYEHGLTFAT IKGAGHTVPEYKPOEAFAFYSRHL-AGSKL CPD-M II, B-chain: EVGGWSOVYKGLTLVSVRGAGHEVVPLHRPR OALLILF O OFL Q GKPMPGRTT N CPD-M III: CPD-Y: - - AGVLKSHGALSFLKVHNAGHMVPMDOPRKAALEMLRRFT QGKLK EVAGEVKSYKHFTYLRVFNGGHUVPF DVPENLLSMVNEWIHGGFSL 
malt carboxypeptidase III with those of other proteins by a computer search of a sequence data base provided by the National Biomedical Research Foundation, demonstrated homology only with malt carboxypeptidase I, wheat and malt carboxypeptidase II, a putative wheat carboxypeptidase and carboxypeptidase Y. Alignment of the three malt carboxypeptidases with carboxypeptidase $\mathrm{Y}$ is shown in Figure 8 with due allowance for gaps. The number of identical amino acid residues in malt carboxypeptidase III and carboxypeptidase $\mathrm{Y}$ is 141 (34\%), whereas only $108(26 \%)$ and $104(25 \%)$ residues are common in malt carboxypeptidase I or malt carboxypeptidase II, respectively. These results are unexpected, because they indicate that malt carboxypeptidase III is more closely related to carboxypeptidase $\mathrm{Y}$ from yeast than to the two other malt carboxypeptidases. This conclusion is supported by the positions of the cysteinyl residues: All the nine cysteinyl residues of malt carboxypeptidase III are found in homologous positions in carboxypeptidase $\mathrm{Y}$. This implies that the disulfide bridges are conserved as well and hence a similar folding of the polypeptide backbone in the two enzymes. Consequently, the free sulfhydryl group of malt carboxypeptidase III (6) is most likely located in position 341 (Figure 8) where the free sulfhydryl group of carboxypeptidase $Y$ is known to be situated (5). Carboxypeptidase $\mathrm{Y}$ contains two additional cysteinyl residues (Cys ${ }^{193}$ and $\mathrm{Cys}^{207}$ ) which are known to be connected by a disulfide bridge (18). A comparison of malt carboxypeptidase I and II reveals that they have six cysteinyl residues in homologous positions, and three of these (residue 56, 268 and 298 in Figure 8) are conserved in malt carboxypeptidase III and carboxypeptidase $\mathrm{Y}$ as well.
The number of identical amino acid residues present in all four carboxypeptidases (Figure 8) is $57(14 \%) .12$ of these residues, corresponding to $21 \%$, are glycyl residues and 8 residues, corresponding to $14 \%$, are prolyl residues. As glycine and proline are known to be situated at bends or twists of the polypeptide chain, these high figures further underline that the spatial conformations of these polypeptide chains might be similar.

Two regions in the four enzymes are highly conserved, i.e. the regions 49-58 and 144-149 in the carboxypeptidase $Y$ numbering. The essential $\operatorname{Ser}^{146}$ of carboxypeptidase Y (12) is located in the latter region and the conservation of this residue in all four carboxypeptidases suggests that it is the active site serine in these enzymes as well. The conserved region, residue $49-58$, is probably important for the three-dimensional structure of the enzymes, due to the presence of three glycines and one proline in this segment.

Recently, it has been shown that $\mathrm{His}^{397}$ is the essential histidyl residue functioning as an acid/ base catalyst in the active site of carboxypeptidase $Y(3)$. As this histidine is the only conserved histidine in all the presently characterized serine carboxypeptidases, it is probably the essential histidine in these enzymes as well. It is still not clear which of the aspartic acid residues participate in the active site (1), since four aspartic acid residues are conserved in all four enzymes.

\section{ACKNOWLEDGEMENTS}

We are grateful to Professor MARTIN OTTESEN for helpful discussions during this work and a critical revision of the manuscript.

The authors wish to acknowledge Mr. THORKILD BEENFELDT for excellent technical assis-

Figure 8. Alignment of the sequences of malt carboxypeptidases I, II and III with the nucleotide derived amino acid sequence of carboxypeptidase $Y$ (nucleotide sequence differs from the amino acid sequence at four positions (5)). His $^{66}$ in malt carboxypeptidase I originates from nucleotide sequencing (10) while Pro was found by amino acid sequencing (19). The numbering is that of carboxypeptidase $Y$. Gaps $(-)$ were introduced to obtain maximum homology. In the sequence of carboxypetidase $Y$ the unblocked cysteinyl residue is indicated by $\mathrm{SH}$, the reactive seryl residue by an asterisk (*) and the essential $\mathrm{His}^{397}$ by $\$$. Substrate binding sites in carboxypeptidase $\mathrm{Y}$ are marked by . Residues identical in all four enzymes are in boxes. $N$ are glycosylated asparagines and $X$ the unknown $\mathrm{N}$-terminal blocking groups. CPD-M I = malt carboxypeptidase I; CPD-M II = malt carboxypeptidase II; CPD-M III = malt carboxypeptidase III; CPD-Y = carboxypeptidase $\mathrm{Y}$. 
tance with preparation of enzyme and Mss. PIA Breddam, Bodil Corneliussen and LONE SøRENSEN for the amino acid analyses and sequencing. Cand.scient. TORBEN Graves PEDERSEN is thanked for help with a computer search of a protein sequence data base provided by the National Biomedical Research Foundation.

\section{REFERENCES}

1. Bachovchin, W.W \& J.D. Roberts: Nitrogen-15 nuclear magnetic resonance spectroscopy. The state of histidine in the catalytic triad of $\alpha$-lytic protease. Implications for the charge-relay mechanism of peptide-bond cleavage by serine proteases. J. Am. Chem. Soc. 100, 8041-8047 (1978)

2. Baulcombe, D.C., R.F. BARKer \& M.G. JARVIS: A gibberellin responsive wheat gene has homology to yeast carboxypeptidase Y, J. Biol. Chem. 262, 13726-13735 (1987)

3. BECH, L.M. \& K. BREDDAM: Inactivation of carboxypeptidase $\mathrm{Y}$ by mutational removal of the essential histidyl residue. Carlsberg Res. Commun. 54, 165-171 (1989)

4. BREDDAM, K.: Serine carboxypeptidases. A review. Carlsberg Res. Commun. 51, 83-128 (1986)

5. BREDDAM, K \& I. SVENDSEN: Identification of methionyl and cysteinyl residues in the substrate binding site of carboxypeptidase Y. Carlsberg Res. Commun. 49, 639-645 (1984)

6. BREDdam, K. \& S.B. Sørensen: Isolation of carboxypeptidase III from malted barley by affinity chromatography. Carlsberg Res. Commun. 52, 275-283 (1987)

7. Breddam, K., S.B. Sørensen \& M. Ottesen: Isolation of a carboxypeptidase from malted barley by affinity chromatography. Carlsberg Res. Commun. 48, 217-230 (1983)

8. Breddam, K., S.B. SøRENSEN \& M. OtTESEN: Isolation of carboxypeptidase II from malted barley by affinity chromatography. Carlsberg Res. Commun. 50, 199-209 (1985)

9. Breddam, K.. S.B. Sørensen \& I.Svendsen: Primary structure and enzymatic properties of carboxypeptidase II from wheat bran. Carlsberg Res. Commun. 52, 297-311 (1987)
10. DOAN, N.P. \& G.B. FinChER: The A- and B-chains of carboxypeptidase I from germinated barley originate from a single precursor polypeptide. J. Biol. Chem. 263, 11106-11110 (1988)

11. Dreyer, T.: Substrate specificity of proteinase yscA from Saccharomyces cerevisiae. Carlsberg Res. Commun. 54, 85-97 (1989)

12. Hayashi, R., S. Moore \& W.H.Stein: Serine at the active center of yeast carboxypeptidase. J. Biol. Chem. 248, 8366-8369 (1973)

13. Houmard, J. \& G.R. Drapeau: Staphylococcal protease: A proteolytic enzyme specific for glutamoyl bonds. Proc. Natl. Acad. Sci. USA 69, 3506 3509 (1972)

14. Johansen, J.T., C. Overballe-Petersen, B. MarTIN, V. HASEMANN \& I. SVENDSEN: The complete amino acid sequence of copper, zinc superoxide dismutase from Saccharomyces cerevisiae. Carlsberg Res. Commun. 44, 201-217 (1979)

15. Martin, B.M., I. SVEndsen, T. Viswanatha \& J.T JOHANSEN: Amino acid sequence of carboxypeptidase Y. I. Peptides from cleavage with cyanogen bromide. Carlsberg Res. Commun. 47, 1-13(1982)

16. Mikola. L.: Germinating barley grains contain five acid carboxypeptidases with complementary substrate specificities. Biochim. Biophys. Acta 747 , 241-252 (1983)

17. SvendSen, I., B. Martin \& I. Jonassen: Characteristics of Hiproly barley III. Amino acid sequences of two lysine-rich proteins. Carlsberg Res. Commun. 45, 79-85 (1980)

18. Svendsen, I., B.M. Martin, T. Viswanatha \& J.T. JOHANSEN: Amino acid sequence of carboxypeptidase Y. II. Peptides from enzymatic cleavages. Carlsberg Res. Commun. 47, $15-27$ (1982)

19. Sørensen, S.B., K. Breddam \& I. Svendsen: Primary structure of carboxypeptidase I from malted barley. Carlsberg Res. Commun. 51, 475-485 (1986)

20. Sørensen, S.B., I. Svendsen \& K. Breddam: Primary structure of carboxypeptidase II from malted barley. Carlsberg Res. Commun. 52, 285-295 (1987)

21. Winspear, M.J., K.R. Preston, V. Rastogi \& A. OAKS: Comparisons of peptide hydrolase activities in cereals. Plant Physiol. 75, 480-482 (1984)

Accepted by E. LUND 